Editorial

\title{
Controversies in the Use and Periodicity of Mammography as a Screening Method for Breast Cancer
}

\section{Controvérsias no uso e periodicidade de mamografia para diagnóstico de câncer de mama}

\author{
Rogério Bonassi Machado ${ }^{1, *}$ \\ ${ }^{1}$ Department of Gynecology and Obstetrics, Faculdade de Medicina \\ de Jundiaí, Jundiaí, SP, Brazil \\ Rev Bras Ginecol Obstet 2018;40:169-170.
}

Mammography has been used as a preparatory method for breast cancer screening, considering different protocols for specific age groups, which suggest the periodicity of its undertaking. The exam is considered necessary, both by physicians and the public, in population strategies to reduce mortality caused by breast cancer. However, studies have questioned the benefit of the periodic mammographic screening. In Canada, an analysis of women between 40 and 59 years old submitted to an annual mammography test for 5 consecutive years showed that there was no significant reduction in mortality rates associated with breast cancer. ${ }^{1}$ In the United Kingdom, annual mammographic screening in women between 39 and 41 years old for 7 years resulted in a nonsignificant advantage. ${ }^{2}$ These studies indicate that mammographic screening does not seem to offer benefits to prevent breast cancer in low- or medium-risk women.

From an epidemiological perspective, screening assumes the use of mammography in healthy women to detect suspected cancer, which will subsequently be submitted to specific diagnostic tests to confirm the disease and guide the treatment. A better mammographic screening approach would effectively reduce death rates in women who undergo this type of exam. Any case of cancer detected through screening should be treated and followed-up over a long period of time for professionals to verify its impact on mortality rates. When mortality rates associated with breast cancer are compared, it is necessary to separate the cases which were detected, treated and followed-up in screening programs from those in which the diagnosis was performed

\footnotetext{
* President of the Brazilian Commission for Contraception at FEBRASGO, Brazil.
}

without screening mammography, according to the disease stage indicated by the diagnosis.

In this scenario, which confronts recent studies and the traditional epidemiological concept, it is important to stress the fact that the detection of a breast cancer case through mammographic screening does not guarantee that the death risk by the disease is reduced. Consequently, part of the controversy results from the confusion about what is known as early detection versus method efficacy. It is believed that a few biases are responsible for the questioning of mammographic screening, such as execution time, selection bias, and especially overdiagnosis. ${ }^{3}$ The latter consists of diagnosing a disease that will lead to neither symptoms nor death. The Canadian study previously mentioned detected $26 \%$ of overdiagnosis, and the number can reach up to $50 \%$ if cases of ductal carcinoma in situ are included, as revealed by a 25 -year follow-up. ${ }^{1}$ In the oncology field, overdiagnosis is defined as the detection of cancer that would not have evolved to be clinically detectable. The type of cancer most frequently detected through mammographic screening is ductal carcinoma in situ, and studies have not shown significant effects of this tumor on women's survival after 20 years of follow-up post- diagnosis. ${ }^{4}$

Previous investigations demonstrated that the probability of a woman who had a cancer diagnosis receiving an overdiagnosis is $19 \%{ }^{5-7}$ Applying this value to the recent cumulative incidence of breast cancer in the United Kingdom (invasive and in situ) means that 1 out of 77 women screened from 55 to 70 years would have an overdiagnosed breast cancer. Authors also claim that the consequences of overdiagnosis are unnecessary surgeries, radiotherapy, and chemotherapy. Nevertheless, they conclude that it is impossible to distinguish between lifethreatening carcinomas and overdiagnoses initially, and that

Copyright $\odot 2018$ by Thieme Revinter

Publicações Ltda, Rio de Janeiro, Brazil

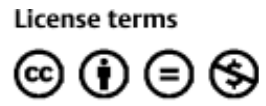

Rogério Bonassi Machado, MD, PhD, President of the Brazilian Commission for Contraception at FEBRASGO, Brazil, Faculdade de Medicina de Jundiaí, R. Francisco Teles, 250 - Vila Arens II, Jundiaí, SP, 13202-550, Brazil (e-mail: rogeriobonassi@terra. com.br).
DOI https://doi.org/ 10.1055/s-0038-1648218. ISSN 0100-7203. 
further studies assessing accurate overdiagnosis rates are fundamental. There are other issues associated with mammographic screening, although they are more infrequent. Around $4 \%$ of women submitted to the test are called to repeat the exam and possibly undergo a biopsy. ${ }^{8}$ Among them, $20 \%$ will have cancer, $70 \%$ will need further imaging studies, and 30\% will require biopsy, procedures that cause psychological damage and anxiety. ${ }^{8}$

The main question concerning the implementation of screening programs relates to the disease mortality though. The first conclusions regarding breast cancer mortality are based on a Cochrane systematic review. ${ }^{9}$ The global relative risk, comparing screened and non-screened women, is 0.80 (confidence interval of $95 \%, 0.73-0.89$ ), that is, the reduction in relative risk of breast cancer mortality in screened women is $20 \%{ }^{9}$

In terms of absolute gain, women screened from 50 to 70 years will experience no benefit in the first 5 years of screening, but mortality reduction will last for 10 years after the last exam. Regarding the direct impact on deaths provoked by breast cancer, 1 death will be prevented in a group of 235 screened women. $^{9}$

Despite the data from studies performed in developed countries, reflections are necessary when the Brazilian reality is evaluated. In our country, $40 \%$ of 50 - to 69 -year-old women do not undertake mammograms. ${ }^{10}$ Consequently, our context still needs improvement in the potential of basic screening for the disease. Taking into account that the Brazilian female population between 50 and 69 years is around 15 million, $^{11}$ and that $60 \%$ of these women are effectively screened through mammography, there would be 40 thousand breast cancer-related deaths prevented.

There is a striking contrast between developed and developing countries when it comes to unmet needs. In the former, mammographic screening is questioned and efforts are made toward breast cancer therapy, which is undeniably the main factor associated with decreased mortality rates. Developing countries still have a great challenge to increase effective screening rates. The Brazilian reality seems not to allow the dismissal of mammography in breast cancer screening. However, faced with current evidence, women must be informed about the benefits and potential risks of overdiagnosis, so their decision on participating in a screening program is as clarified as possible.

\section{References}

1 Miller AB, Wall C, Baines CJ, Sun P, To T, Narod SA. Twenty five year follow-up for breast cancer incidence and mortality of the Canadian National Breast Screening Study: randomised screening trial. BMJ 2014;348:g366

2 Moss SM, Wale C, Smith R, Evans A, Cuckle H, Duffy SW. Effect of mammographic screening from age 40 years on breast cancer mortality in the UK Age trial at 17 years' follow-up: a randomised controlled trial. Lancet Oncol 2015;16(09):1123-1132

3 Miller AB. Fundamental issues in screening for cancer. In: Schottenfeld D, Fraumeni JF Jr, eds. Cancer Epidemiology and Prevention. 2nd ed. New York, Oxford: Oxford University Press; 1996:1433-1452

4 Esserman LJ, Thompson IM, Reid B, et al. Addressing overdiagnosis and overtreatment in cancer: a prescription for change. Lancet Oncol 2014;15(06):e234-e242

5 Bleyer A, Welch HG. Effect of three decades of screening mammography on breast-cancer incidence. N Engl J Med 2012;367 (21):1998-2005

6 Autier P, Boniol M, Gavin A, Vatten LJ. Breast cancer mortality in neighbouring European countries with different levels of screening but similar access to treatment: trend analysis of WHO mortality database. BMJ 2011;343:d4411

7 Paci E; EUROSCREEN Working Group. Summary of the evidence of breast cancer service screening outcomes in Europe and first estimate of the benefit and harm balance sheet. J Med Screen 2012;19(Suppl 1):5-13

8 Miller $\mathrm{AB}$. The role of screening mammography in the era of modern breast cancer treatment. Climacteric 2018;17:1-5

9 Gøtzsche PC, Nielsen M. Screening for breast cancer with mammography. Cochrane Database Syst Rev 2011;(01):CD001877

10 Instituto Brasileiro de Geografia e Estatística. Pesquisa Nacional de Saúde 2013: percepção do estado de saúde, estilo de vida e doenças crônicas - Brasil, grandes regiões e unidades da federação. Rio de Janeiro: IBGE; 2014. Available at: http://www. ibge. gov.br/home/estatistica/populacao/pns/2013/

11 Instituto Brasileiro de Geografia e Estatística. Censo Demográfico 2010. Available at: https://censo2010.ibge.gov.br/sinopse/index. php?dados $=12$ 